\title{
Analysis of risk factors of ST-segment elevation myocardial infarction in young patients
}

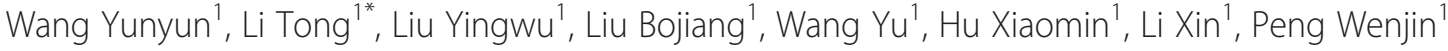 \\ and JinFang $L i^{2}$
}

\begin{abstract}
Background: Acute myocardial infarction (AMI) is often present in old populations and rare in young people. Its incidence significantly increased recent years. The mechanism and disease course of AMI in young people are probably different from that in old population. The aim of this study was to analyze clinical risk factors of STEMI in young patients.
\end{abstract}

Methods: Data was collected from consecutive patients $\leq 44$ years of age (young; $n=86$ ) and $60-74$ years of age (old; $n=65$ ) diagnosed with STEMI, and 79 young age-matched patients without coronary artery disease (CAD), hospitalized between January 2009 and June 2013.

Results: The young STEMI group had a significantly higher proportion of males (88.37 vs. $53.16 \% ; P<0.01$ ), smokers (82.56 vs. 49.37\%; $P<0.01)$ and patients with a family history of early CAD (54.65 vs. $32.91 \% ; P<0.05)$ than age-matched controls. Young STEMI patients also had significantly higher levels of fasting blood sugar $(6.39 \mathrm{vs} .5 .25 \mathrm{mmol} / \mathrm{L}$; $P<0.001$ ), glycated hemoglobin (HbA1c) (6.26 vs. 5.45\%; $P<0.05$ ), total cholesterol (5.14 vs. $4.65 \mathrm{mmol} / \mathrm{L}, P<0.05)$, and fibrinogen (Fib) (3.39 vs. 2.87; $P<0.01$ ). Compared with the old STEMI group, young STEMI patients had significantly higher proportions of males (88.37 vs. $63.08 \%$; $P<0.01$ ) smokers ( 82.56 vs. $41.54 \% ; P<0.01$ ), and those with a family history of early CAD (54.65 vs. 18.46\%; $P<0.01$ ). Young STEMl patients also lower Fib (3.39 vs. $3.88 \mathrm{~g} / \mathrm{L} ; P<0.01$ ), less frequent occurrence of angina pectoris before STEMI (13.95 vs. 29.23\%; $P<0.05)$ compared with the old STEMI group. Logistic regression analysis indicated that male sex $(O R=5.891)$, smoking $(O R=3.500)$, family history of early $C A D$ $(\mathrm{OR}=3.194)$, Fib $(\mathrm{OR}=2.414)$ and $\mathrm{HbA1c}(\mathrm{OR}=1.515)$ are associated with STEMl in young patients.

Conclusion: In addition to previously recognized risk factors (male sex, smoking and family history of early CAD), Fib and $\mathrm{HbA1C}$ are associated with STEMI in individuals $\leq 44$ years of age without antecedent angina pectoris.

Keywords: Antecedent angina pectoris, Fibrinogen, Glycated hemoglobin, Risk factors, ST-segment elevation myocardial infarction, Young patients

\section{Background}

Acute myocardial infarction (AMI) is a major cause of death worldwide. AMI is less frequent in adults younger than 45 years of age than in elderly adults [1,2], but is of increasing clinical interest in young adults because of the potential of premature death and long-term disability [3]. The incidence of AMI in young people was as low as $2-6 \%[1,2]$, but has recently begun to rise. The protection offered by young age is countered by increased prevalence of risk factors for coronary artery disease

\footnotetext{
* Correspondence: litong3zx@sina.com

'Cardiac Center, Third Central Hospital of Tian Jin, Tian Jin 300170, China

Full list of author information is available at the end of the article
}

(CAD), such as impaired glucose tolerance and obesity, in adolescence [4]. Ignorance of CAD combined with a false sense of security likely prevents younger individuals from seeking medical advice. Early recognition and risk factor modification in this population is of key importance [5].

The mechanism and disease course of AMI in young patients are likely different from those in an older population, and knowing of theses differences may help to prevent the disease and improve the prognosis [6]. However, there are few studies investigating risk factor profiles and patterns of coronary artery involvement in ST-segment elevation myocardial infarction (STEMI) in younger individuals. This 
paper retrospectively analyzed risk factors and clinical features in young patients with STEMI to characterize this medical condition.

\section{Methods}

\section{Ethics statement}

This study was approved by ethics committee of The Third Central Hospital of Tian Jin. The study protocols comply with the ethical guidelines of the Declaration of Helsinki. All subjects provided informed consent.

\section{Subjects}

This was a retrospective study of 86 consecutive young patients (18-44 years of age) with STEMI selected from a total of 2460 AMI patients enrolled between January 2009 and June 2013 at The Third Central hospital of Tianjin. A group of 79 young adults of the same age range who made consecutive visits to the hospital during the same period, were enrolled as controls. Coronary heart disease was excluded in this group by coronary angiography. An additional group of 65 consecutive old patients (60-74 years of age) with STEMI were included for comparison.

\section{Inclusion criteria}

Patients included in the study were diagnosed with STEMI, defined by the typical rise and fall of cardiac markers of myocardial necrosis with at least one of the following [7]: i) symptoms of ischemia; ii) echocardiogram changes indicative of new ischemia $(\geq 0.1 \mathrm{mV}$ in two or more standard leads, $\geq 0.2 \mathrm{mV}$ in two or more contiguous pre-cordial leads, or a new left bundle branch block); iii) $12 \mathrm{~h}$ after symptoms, levels of creating kinase and its isoform (CKMB) were twice the normal upper limit or a troponin level was increased to the standard of MI (according to the normal local laboratory value). All patients had complete medical records and had undergone coronary angiography.

\section{Exclusion criteria}

Patients with the following conditions were excluded: congenital heart disease, cardiomyopathy, myocarditis, Takayasu's arteritis or vascular dysplasia; coronary artery embolism; AMI secondary to aortic dissection, severe aorta valve stenosis, myocardial hypertrophy, and history of AMI without evidence from angiography showing narrowing of the coronary arteries.

\section{Data collection}

Demographic and baseline data were collected by questionnaire at patient interviews and by review of medical records. Medical records were analyzed for the patients' CAD risk factor profiles. Baseline data included gender, age, body mass index, history of smoking or drinking, family history of CAD, medical history of hypertension, type II diabetes mellitus, cranial vascular accidents, systolic and diastolic pressure, and the presence of other diseases. A TBA-120FR auto-biochemical analyzer (Toshiba, Japan) and Sysmex kx-21 hematology analyzer (Sysmex, Japan) were used to measure fasting blood sugar, glycated hemoglobin (HbA1c), creatine kinase and CKMB, troponin I (normal range 0.05-0.40 ng/mL), triglycerides (TG), total cholesterol (TC), non-high-density lipoprotein cholesterol (NHDL-C), HDL-C, and fibrinogen (Fib) in the morning after hospital admission, following an overnight fast.

\section{Criteria for other conditions}

Hypertension was defined as a systolic pressure $\geq$ $140 \mathrm{mmHg}$ and/or a diastolic pressure $\geq 90 \mathrm{mmHg}$ [8]; a history of hypertension was noted in patients using antihypertension medications. Type II diabetes was noted in patients who met the 1999 WHO diagnosis criteria [9]. Unstable angina pectoris (AP) before AMI included initial AP on effort, exacerbation of effort AP, spontaneous AP, mixed AP, variant angina, and angina that occurred within one month of AMI, each episode lasting 220 min [10]. Smoking was defined as smoking for six months or longer, and a smoking index was calculated as the number of daily cigarettes $\times$ years of smoking [11]. A family history of early CAD was recorded in patients where it was first diagnosed in the father at $\leq 55$ or the mother at $\leq 65$ years of age.

\section{Coronary angiography}

Due to delays for hospital admittance in some patients, coronary angiography was performed within one month after STEMI via the radial artery using a multifunction catheter or via the femoral artery using the Judkins method. The results were interpreted by two experienced physicians.

\section{Statistical analysis}

SPSS 17.0 software (SPSS Inc., Chicago, IL, USA) was used for all data analysis. Normally distributed numeric data are presented as means \pm standard deviation and intergroup comparisons were conducted with a Student's $t$-test. Non-normally distributed numeric data are presented as medians and quartiles (M [Q1, Q3]) and intergroup comparisons were conducted with the MannWhitney $U$ test. Categorical data were tested with the $\chi^{2}$ test. A logistic regression model was used to identify risk factors of STEMI in young patients. All tests were two sided and $P<0.05$ was regarded as significant.

\section{Results}

Comparison between young STEMI and control patients Baseline clinical and laboratory test data in the young STEMI and young control groups are summarized in 
Table 1. The proportions of smokers and patients with a family history of early CAD, and the smoking index values in the STEMI group were significantly higher than those in the control group $\left(P_{\mathrm{S}}<0.05\right)$. STEMI patients had significantly higher fasting blood sugar, HbAlc, TC, NHDL-C and Fib levels than controls $(P \mathrm{~s}<0.05)$. There were no differences between the two groups in age, blood pressure, TG, HDL-C, hypertension, type II diabetes, cerebrovascular diseases, or drinking.

\section{Comparison between young and old STEMI patients}

Baseline clinical and laboratory test data in the young and old STEMI groups are summarized in Table 2. The gender, diastolic pressure, pulse pressure, smoking, smoking index values, and family history of early $C A D$ were significantly different between the two groups $\left(P_{\mathrm{S}}<0.05\right)$. Patients in the

Table 1 Clinical data from the young groups

\begin{tabular}{|c|c|c|c|}
\hline Variable & $\begin{array}{l}\text { STEMI } \\
(n=86)\end{array}$ & $\begin{array}{l}\text { Control } \\
(n=79)\end{array}$ & $P$ \\
\hline Age, y & $40.00(23,44)$ & $39.94(27,44)$ & 0.317 \\
\hline Male, $n(\%)$ & $76(88.37)$ & $42(53.16)$ & $<0.001$ \\
\hline BMI $\left(\mathrm{kg} / \mathrm{m}^{2}\right)$ & $27.96 \pm 2.80$ & $25.16 \pm 3.15$ & 0.127 \\
\hline Systolic pressure (mmHg) & $133.59(90,200)$ & $134.82(100,190)$ & 0.629 \\
\hline Diastolic pressure (mmHg) & $81.03(50,124)$ & $83.37(60,140)$ & 0.957 \\
\hline Pulse pressure (mmHg) & $52.67(25,90)$ & $51.71(30,90)$ & 0.608 \\
\hline $\begin{array}{l}\text { Fasting blood sugar } \\
(\mathrm{mmol} / \mathrm{L})\end{array}$ & $6.39(3.76,18.00)$ & $5.25(3.25,12.35)$ & $<0.001$ \\
\hline $\mathrm{HbA1C}(\%)$ & $6.26 \pm 1.69$ & $5.45 \pm 1.12$ & 0.018 \\
\hline CK (U/L) & $1950.28 \pm 1639.52$ & $81.15 \pm 44.60$ & $<0.001$ \\
\hline CKMB (U/L) & $163.99 \pm 127.38$ & $14.77 \pm 13.35$ & $<0.001$ \\
\hline TNI (ng/mL) & $3.08(0.11,30)$ & $0.07(0.05,0.3)$ & $<0.001$ \\
\hline TG $(m m o l / L)$ & $2.37 \pm 2.48$ & $2.25 \pm 1.26$ & 0.201 \\
\hline TC (mmol/L) & $5.14 \pm 1.39$ & $4.65 \pm 0.87$ & 0.002 \\
\hline NHDL-C (mmol/L) & $4.06 \pm 1.35$ & $3.53 \pm 0.87$ & 0.002 \\
\hline $\mathrm{HDL}-\mathrm{C}(\mathrm{mmol} / \mathrm{L})$ & $1.07 \pm 0.27$ & $1.12 \pm 0.26$ & 0.856 \\
\hline $\mathrm{Fib}(\mathrm{g} / \mathrm{L})$ & $3.39(1.90,7.52)$ & $2.87(1.78,5.30)$ & $<0.001$ \\
\hline Hypertension, n (\%) & $41(47.67)$ & $35(44.30)$ & 0.755 \\
\hline Type II diabetes, n (\%) & $18(20.93)$ & $17(21.52)$ & 1.000 \\
\hline $\begin{array}{l}\text { Cerebrovascular diseases, } \\
n(\%)\end{array}$ & $6(6.98)$ & $2(2.53)$ & 0.281 \\
\hline Alcohol drinking, $n$ (\%) & $25(29.07)$ & $19(24.05)$ & 0.486 \\
\hline Smoking, $n(\%)$ & $71(82.56)$ & $39(49.37)$ & $<0.001$ \\
\hline Smoking index & $329.53(0,1200)$ & $179.49(0,900)$ & $<0.001$ \\
\hline $\begin{array}{l}\text { Family history of } \\
\text { early CAD, } n(\%)\end{array}$ & $47(54.65)$ & $26(32.91)$ & 0.007 \\
\hline
\end{tabular}

Abbreviations: $B M I$ body mass index, $C A D$ coronary artery disease, $C K$ creatine kinase, CKMB isoform of CK, Fib fibrinogen, $\mathrm{HbA1C}$ glycated hemoglobin, $H D L-C$ high-density lipoprotein cholesterol, $M I$ myocardial infarction, $N H D L-C$ nonHDL-C, TC total cholesterol, TG triglyceride, TNI troponin I, STEMI ST-segment elevation myocardial infarction.

Note: Data are expressed as mean \pm standard deviation or medians (Q1, Q3).
Table 2 Comparison of young and old STEMI groups

\begin{tabular}{|c|c|c|c|}
\hline Variable & $\begin{array}{l}\text { Young } \\
(n=86)\end{array}$ & $\begin{array}{c}\text { Old } \\
(n=65)\end{array}$ & $P$ \\
\hline Age, y & $40.00(23,44)$ & $69.15(63,74)$ & $<0.001$ \\
\hline Male, $n(\%)$ & $76(88.37)$ & $41(63.08)$ & 0.001 \\
\hline BMI, $\mathrm{kg} / \mathrm{m}^{2}$ & $27.96 \pm 2.80$ & $26.18 \pm 2.30$ & 0.346 \\
\hline Systolic pressure, mmHg & $133.59(90,200)$ & $131.09(96,180)$ & 0.885 \\
\hline Diastolic pressure, $\mathrm{mmHg}$ & $81.03(50,124)$ & $73.20(46,120)$ & 0.005 \\
\hline Pulse pressure, $\mathrm{mmHg}$ & $52.67(25,90)$ & $57.89(30,100)$ & 0.030 \\
\hline $\begin{array}{l}\text { Fasting blood sugar } \\
(\mathrm{mmol} / \mathrm{L})\end{array}$ & $6.39(3.76,18.00)$ & $6.02(3.61,12.00)$ & 0.682 \\
\hline $\mathrm{HbA} 1 \mathrm{C}(\%)$ & $6.26 \pm 1.69$ & $6.29 \pm 1.47$ & 0.458 \\
\hline CK $(U / L)$ & $1950.28 \pm 1639.52$ & $1691.35 \pm 1411.02$ & 0.533 \\
\hline CKMB (U/L) & $163.99 \pm 127.38$ & $189.14 \pm 173.26$ & 0.066 \\
\hline TNI (ng/mL) & $3.08(0.11,30)$ & $3.40(0.17,30)$ & 0.664 \\
\hline $\mathrm{TG}(\mathrm{mmol} / \mathrm{L})$ & $2.37 \pm 2.48$ & $1.29 \pm 0.48$ & 0.001 \\
\hline $\mathrm{TC}(\mathrm{mmol} / \mathrm{L})$ & $5.14 \pm 1.39$ & $4.74 \pm 0.85$ & 0.005 \\
\hline $\mathrm{NHDL}-\mathrm{C}(\mathrm{mmol} / \mathrm{L})$ & $4.06 \pm 1.35$ & $3.60 \pm 0.76$ & 0.003 \\
\hline $\mathrm{HDL}-\mathrm{C}(\mathrm{mmol} / \mathrm{L})$ & $1.07 \pm 0.27$ & $1.14 \pm 0.24$ & 0.760 \\
\hline $\mathrm{Fib}(\mathrm{g} / \mathrm{L})$ & $3.39(1.90,7.52)$ & $3.88(2.06,10.94)$ & $<0.001$ \\
\hline Hypertension, n (\%) & $41(47.67)$ & $35(53.85)$ & 0.512 \\
\hline Type II diabetes, n (\%) & $18(20.93)$ & $21(32.30)$ & 0.135 \\
\hline $\begin{array}{l}\text { Cerebrovascular diseases, } \\
n(\%)\end{array}$ & $6(6.98)$ & $18(27.69)$ & $<0.001$ \\
\hline Alcohol drinking, $n(\%)$ & $25(29.07)$ & $7(10.77)$ & 0.008 \\
\hline Smoking, $n(\%)$ & $71(82.56 \%)$ & $27(41.54)$ & $<0.001$ \\
\hline Smoking index & $329.53(0,1200)$ & $263.54(0,2400)$ & $<0.001$ \\
\hline $\begin{array}{l}\text { Family history of early } \\
\text { CAD, } n(\%)\end{array}$ & $47(54.65)$ & $12(18.46)$ & $<0.001$ \\
\hline $\begin{array}{l}\text { Angina pectoris before } \\
M I, n(\%)\end{array}$ & 12 (13.95) & 19 (29.23) & 0.026 \\
\hline
\end{tabular}

Abbreviations: $B M I$ body mass index, $C A D$ coronary artery disease, $C K$ creatine kinase, CKMB isoform of CK, Fib fibrinogen, HbA1c glycated hemoglobin, HDL-C high-density lipoprotein cholesterol, MI myocardial infarction, NHDL-C nonHDL-C, STEMI ST-segment elevation myocardial infarction, TC total cholesterol $T G$ triglyceride, $T N /$ troponin I.

Note: Data are expressed as mean \pm standard deviation or medians (Q1, Q3).

young group were less likely to have cerebrovascular diseases or experience AP before STEMI than the older patients. TG, TC, and NHDL-C levels were higher, and serum Fib was lower, in young compared with old STEMI patients $(P \mathrm{~s}<0.05)$. Smoking and imbalance of lipid metabolism were more common in young STEMI patients than in old patients $\left(P_{\mathrm{S}}<0.05\right)$.

\section{Risk factors of STEMI}

Using STEMI as a dependent variable, independent risk factors among young patients were determined as those with a $P<0.25$ in Student's $t$-tests, including gender, smoking history, smoking index, family history of early CAD, and levels of blood sugar, HbA1c, TC, NHDL-C, 
and Fib, and assessed by a logistic regression analysis. The analysis revealed that gender, smoking, family history of CAD, Fib, and $\mathrm{HbA1c}$ levels were independent risk factors for STEMI in young individuals $(P \mathrm{~S}<0.05)$ (Table 3).

\section{Discussion}

The lifestyles of young people, characterized by high work stress, fast pace, overwork, smoking, drinking alcohol, and overeating, likely cause disturbances in the internal environment, such as coronary atherosclerosis, that increase the incidence of AMI [12]. Atherosclerosis, which is affected by many factors, may cause coronary spasms or broken plaque in coronary arteries resulting in acute blockage [13]. In this study, we found that STEMI tended to occur suddenly in young patients and in those without a history of AP.

Conventional risk factors for STEMI include male sex, smoking, and a family history of early CAD [14]. In accordance with this and another study [15], we found that male sex was an important risk factor for STEMI in young patients. Androgen was shown to negatively correlate with the incidence of STEMI, and physiologic levels can prevent atherosclerosis [16]. Androgen levels, which peak at age 20-24 and then decline gradually, are significantly reduced in atherosclerosis patients, and low androgen levels can induce heart diseases and predict AMI [17]. The unhealthy habits such as smoking, drinking, and eating high-fat or high-purine diets may also increase the risk of AMI in young men compared with older male and young female populations. This may explain why the group of young STEMI patients included a significantly higher proportion of males than the old group.

A recent study published by Cases and Rate [18] found that among 6892 STEMI who received percutaneous coronary intervention, $46.4 \%$ were smokers, compared with $20.5 \%$ in the general population. Studies in China and other countries demonstrated that young AMI patients have smoking rates as high as $70-90 \%[5,19]$. As our data show, young STEMI patients are more likely

Table 3 Logistic regression analysis of STEMI risk factors in young patients

\begin{tabular}{ccccccc}
\hline Factors & B value & SE & Wald & OR & $\mathbf{9 5 \% ~ C l ~}$ & $\boldsymbol{P}$ \\
\hline Male & 1.7731 & 0.508 & 12.177 & 5.891 & $2.176-15.950$ & $<0.001$ \\
Smoking history & 1.253 & 0.473 & 7.016 & 3.500 & $1.385-8.842$ & 0.008 \\
$\begin{array}{c}\text { Family history of } \\
\text { early CAD }\end{array}$ & 1.161 & 0.409 & 8.059 & 3.194 & $1.433-7.122$ & 0.005 \\
Fib & 0.881 & 0.288 & 9.366 & 2.414 & $1.373-4.245$ & 0.002 \\
HbA1C & 0.415 & 0.165 & 6.370 & 1.515 & $1.097-2.091$ & 0.012 \\
\hline
\end{tabular}

Abbreviations: $C A D$ coronary artery disease, $\mathrm{Cl}$ confidence interval, Fib fibrinogen, HbA1c glycated hemoglobin, OR odds ratio, SE standard error, STEMI ST-segment elevation myocardial infarction. than older patients to be smokers. The risk of AMI decreases after smokers quit, and the benefit of quitting is correlated with amount smoked [11]. Moreover, smoking cessation can help prevent cardiovascular events, especially in young people [18].

The results of our study show that $58.33 \%$ of young patients have a family history of early CAD, which is higher than the $30-40 \%$ of young AMI patients reported by Colkesen $e t$ al. [20]. Patients with a family history of CAD have more severe disease progression than those without a history [21], more lipid metabolism disorders, and more likely to have insulin resistance and be obese, possibly resulting from hereditary factors [22].

An important finding from our study is that levels of HbA1c and Fib were independent risk factors for STEMI in young patients. Fib is associated with vascular endothelial injury, and enhances the coagulation of platelets and increase in blood viscosity to induce thrombosis. Fib level is significantly associated with coronary artery calcification and sclerosis [23], and levels are significantly higher in patients who die from coronary diseases than in those who survive [24]. A study by Tatli et al. [25] showed that Fib can predict the extent of coronary artery narrowing in young AMI patients. In this study, the Fib levels were significantly higher in young STEMI patients compared with controls, and logistic regression analysis indicated it was an independent risk factor of STEMI, further confirming the role of coagulation disorders in STEMI in the young population. Old STEMI patients also had higher Fib levels, suggesting that its effect in this population is even more important.

Although diabetes is an important risk factor for coronary disease, its incidence was not significantly higher in the young versus the old STEMI patients. However, many studies report that non-diabetic AMI patients have increased blood sugar, compromised glucose tolerance, and insulin resistance [26,27]. There is a significant correlation between $\mathrm{HbA1c}$ level, an indicator of long-term glycemic control, and the development and prognosis of coronary diseases; this correlation is less frequently reported in young patients [28]. In our study, STEMI patients were younger than the peak age of diabetes incidence, though baseline fasting blood sugar and HbA1c were significantly higher, suggesting that a higher proportion of patients had undetected diabetics or prediabetes. As pre-diabetic conditions can influence the course of STEMI, medical intervention in young people may help prevent STEMI. The findings of this study show that whereas fasting blood sugar level is a dependent risk factor, $\mathrm{HbA1c}$ is an independent risk factor, indicating that $\mathrm{HbAlc}$ is more strongly correlated with STEMI in young people.

Unstable AP before AMI is a clinical manifestation of ischemic preconditioning; repeated AP prepares the 
myocardium, reducing myocardial injury, cardiac dysfunction and severe cardiac arrhythmia following AMI [29]. Klein et al. [30] found that young patients seldom experience AP before MI, but that AP quickly progresses to AMI. Consistent with their findings, only $12 \%$ of the young STEMI patients in our study experienced AP before STEMI, a significantly smaller percentage than in old STEMI patients. STEMI in young patients generally has no ischemic preconditioning, and occurs and progresses faster than it does in older patients. However, troponin I values were similar between the young and old STEMI groups, and there were no differences in the degree of myocardial necrosis.

\section{Study limitations}

This study is subject to the usual limitations associated with a retrospective design. Because of the low incidence of STEMI in young people, the sample size of this study was small. Despite adjusting for multiple risk factors, it is possible that there may have been residual confounding conditions and medications. In addition, no data were collected about coronary artery disease extension. Therefore, the influence of some confounders and biases cannot be completely excluded. Multicenter studies with large sample sizes will further elucidate the mechanism of STEMI in the young population. Nevertheless, this study provides a clinical reference for healthcare professionals to more fully understand risk factors in young STEMI patients and to develop early preventative interventions.

\section{Conclusion}

In conclusion, STEMI in young people has some clinical features that are different from those in older patients. In addition to the conventional risk factors, Fib and HbAlc are associated with the initiation of STEMI, and can provide inexpensive and powerful prognostic factors for STEMI in young patients. STEMI in young patients is often accompanied by disorders of glucose metabolism and abnormal coagulation, though AP before STEMI is rare.

\section{Competing interests}

The authors declare that they have no competing interests.

\section{Authors' contributions}

WY carried out the studies of coronary heart disease. WY and LT designed the study and drafted the manuscript. LY and LT conceived of the study. LB, WY, HX, LX and PW participated in the collection of data. LF helped to draft the manuscript. All authors read and approved the final manuscript.

\footnotetext{
Acknowledgements

I would like to express my gratitude to all those who helped me during the writing of this paper

My deepest gratitude goes first and foremost to Professor Li Tong for his constant encouragement and guidance. He has walked me through all the stages of the writing of this paper. Without his consistent and illuminating instruction, this paper could not have reached its present form.

Second, I would like to express my heartfelt gratitude to Professor Liu Yingwu, who conceived of the study and helped to draft the manuscript. I am also greatly indebted to the professors and teachers at the Department
}

of Cardiac Center: Liu Bojiang, Wang Yu, Hu Xiaomin, Li Xin and Peng Wenjin, who have instructed and helped me a lot in the past two years. I am also deeply indebted to Professor JinFang Li,whose profound knowledge of English triggers my love for this beautiful language and whose earnest attitude tells me how to learn English.

Last my thanks would go to my beloved family for their loving considerations and great confidence in me all through these years.

\section{Author details}

${ }^{1}$ Cardiac Center, Third Central Hospital of Tian Jin, Tian Jin 300170, China.

2Essen Medical Associates, P.C.2015 Grand concourse, Bronx, NY 10453, USA.

Received: 22 February 2014 Accepted: 1 December 2014

Published: 9 December 2014

\section{References}

1. Fournier J, Sanchez A, Quero J, Fernandez-Cortacero J, González-Barrero A: Myocardial infarction in men aged 40 years or less: a prospective clinical-angiographic study. Clin Cardiol 1996, 19(8):631-636.

2. Garoufalis S, Kouvaras G, Vitsias G, Perdikouris K, Markatou P, Hatzisavas J, Kassinos N, Karidis K, Foussas S: Comparison of angiographic findings, risk factors, and long term follow-up between young and old patients with a history of myocardial infarction. Int J Cardiol 1998, 67(1):75-80.

3. Weinberger I, Rotenberg Z, Fuchs J, Sagy A, Friedmann J, Agmon J: Myocardial infarction in young adults under 30 years: risk factors and clinical course. Clin Cardiol 1987, 10(1):9-15.

4. Sinha R, Fisch G, Teague B, Tamborlane WV, Banyas B, Allen K, Savoye M, Rieger V, Taksali S, Barbetta G, Sherwin RS, Caprio S: Prevalence of impaired glucose tolerance among children and adolescents with marked obesity. N Engl J Med 2002, 346:802-810.

5. Jamil G, Jamil M, Alkhazraji H, Haque A, Chedid F, Balasubramanian M, Khairallah B, Qureshi A: Risk factor assessment of young patients with ST-segment elevation myocardial infarction. Am J Cardiovasc Dis 2013, 3(3):170-174.

6. Egred M, Viswanathan G, Davis G: Myocardial infarction in young adults. Postgrad Med 2005, 81(962):741-745.

7. Chinese Society of Cardiology of Chinese Medical Association, Editorial committee of Chinese Journal of Cardiology, Editorial committee of Chinese Circulation Journal: Acute myocardial infarction diagnosis and treatment guidelines. Chin J Cardiol (Chin) 2001, 29:710-725.

8. Chinese Hypertension Prevention and Treatment Guide Revision Committee: Chinese hypertension prevention and treatment guide 2004. Chin J Cardiol 2004, 32:1060-1064.

9. Ye RG, Lu ZY, Xie Y, Wang C: Internal Medicine. 6th edition. China: People's Medical Publishing House; 2006:918.

10. Yang YJ, Hua W, Gao RL: Fuwai Cardiovascular Medicine Manual. 1st edition. China: People's Medical Publishing House; 2006:154-173.

11. Zhao J, Hu D-y, Ding R-j, Li XB, Zhang P, Wang L, Yu XJ, Guo JH, Wang XQ Li L, Zhang FF, Huang ZW: Coronary characteristics of young smokers with coronary heart disease and the effects of tobacco control on smoking cessation [J]. Zhonghua Yi Xue Za Zhi 2010, 38(12):1077-1080.

12. Wang $X Y$ : Analysis of 56 young patients with acute myocardial infarction. J Med Theory Pract 2012, 25:917-918.

13. Ma CT, Jiang YX, Du WJ, Liu ZF, Wang J: The correlation analysis of serum BNP, hypersentive C-creative protein and left ventricular ejaction fraction of acute myocardial infarction patients. Chin Crit Care 2012, 24(4):247-248.

14. Schoenenberger AW, Radovanovic D, Stauffer JC, Windecker S, Urban P, Niedermaier G, Keller PF, Gutzwiller F, Erne P: Acute coronary syndromes in young patients: presentation, treatment and outcome. Int J Cardiol 2011, 148(3):300-304.

15. Egiziano G, Akhtari S, Pilote L, Daskalopoulou S: Sex differences in young patients with acute myocardial infarction. Diabet Med 2013, 30(3):e108-e1 14.

16. Provotorov V: Age-related androgen deficiency in men with ischemic heart disease. Adv Gerontol 2007, 21(2):311-313.

17. Zhang $X, L i X, C a O T$, Ye L: Correlation of endogenous androgen and androgen receptor level with coronary artery diseases in elderly males]. Zhonghua Yi Xue Za Zhi 2011, 91(14):984.

18. Cases N, Rate ES: The ongoing importance of smoking as a powerful risk factor for ST-segment elevation myocardial infarction in young patients. JAMA 2013, 173(13):1261 
19. Barbash G, White H, Modan M, Diaz R, Hampton J, Heikkila J, Kristinsson A, Moulopoulos S, Paolasso E, Werf TV: Acute myocardial infarction in the young-the role of smoking. Eur Heart 1995, 16(3):313-316.

20. Colkesen AY, Acil T, Demircan S, Sezgin AT, Muderrisoglu H: Coronary lesion type, location, and characteristics of acute ST elevation myocardial infarction in young adults under 35 years of age. Coron Artery Dis 2008, 19(5):345-347.

21. Gaeta G, De Michele M, Cuomo S, Guarini P, Foglia MC, Bond MG, Trevisan M: Arterial abnormalities in the offspring of patients with premature myocardial infarction. N Engl I Med 2000, 343(12):840-846.

22. Berenson GS, Srinivasan SR, Bao W, Newman WP, Tracy RE, Wattigney WA: Association between multiple cardiovascular risk factors and atherosclerosis in children and young adults. N Engl J Med 1998, 338(23):1650-1656.

23. Bielak LF, Klee GG, Sheedy PF, Turner ST, Schwartz RS, Peyser PA: Association of fibrinogen with quantity of coronary artery calcification measured by electron beam computed tomography. Arterioscler Thromb Vasc Biol 2000, 20(9):2167-2171.

24. Meade T, Chakrabarti R, Haines A, North W, Stirling Y, Thompson S, Brozović M: Haemostatic function and cardiovascular death: early results of a prospective study. Lancet 1980, 315(8177):1050-1054.

25. Tatli E, Ozcelik F, Aktoz M: Plasma fibrinogen level may predict critical coronary artery stenosis in young adults with myocardial infarction. Cardiol J 2009, 16(4):317-320.

26. Tandjung K, van Houwelingen KG, Jansen H, Basalus MW, Sen H, Löwik MM, Stoel MG, Louwerenburg JHW, de Man FH, Linssen G: Comparison of frequency of periprocedural myocardial infarction in patients with and without diabetes mellitus to those with previously unknown but elevated glycated hemoglobin levels (from the TWENTE trial). Am J Cardiol 2012, 110(11):1561-1567.

27. Lazzeri C, Valente S, Chiostri M, Picariello C, Attanà P, Gensini GF: Glycated hemoglobin in ST-elevation myocardial infarction without previously known diabetes: Its short and long term prognostic role. Diabetes Res Clin Pract 2012, 95(1):e14-e16.

28. Timmer JR, Hoekstra M, Nijsten MW, van der Horst IC, Ottervanger JP, Slingerland RJ, Dambrink J-HE, Bilo HJ, Zijlstra F, van't Hof AW: Prognostic value of admission glycosylated hemoglobin and glucose in nondiabetic patients with ST-segment-elevation myocardial infarction treated with percutaneous coronary intervention. Circulation 2011, 124(6):704-711.

29. Przyklenk K, Whittaker $P$ : Brief antecedent ischemia enhances recombinant tissue plasminogen activator-induced coronary thrombolysis by adenosine-mediated mechanism. Circulation 2000, 102(1):88-95.

30. Klein LW, Agarwal JB, Herlich MB, Leary TM, Helfant RH: Prognosis of symptomatic coronary artery disease in young adults aged 40 years or less. Am J Cardiol 1987, 60(16):1269-1272.

doi:10.1186/1471-2261-14-179

Cite this article as: Yunyun et al: Analysis of risk factors of ST-segment elevation myocardial infarction in young patients. BMC Cardiovascular Disorders 2014 14:179.

\section{Submit your next manuscript to BioMed Central and take full advantage of:}

- Convenient online submission

- Thorough peer review

- No space constraints or color figure charges

- Immediate publication on acceptance

- Inclusion in PubMed, CAS, Scopus and Google Scholar

- Research which is freely available for redistribution

Submit your manuscript at www.biomedcentral.com/submit 